\title{
Pareto Improving Tariff Reduction Scheme in an Imperfectly Competitive Model of Trade: A Three-Country Case*
}

\author{
Hisayuki Okamoto \\ Department of Economics, Kobe University of Commerce
}

\begin{abstract}
In this paper we develop a three-country model of international trade with imperfectly competitive good, which consists of two developed countries and one developing country. We analyze comprehensively the effects of a tariff change on the supplies of imperfect competitive good and on the welfare of each country in the most general framework, i.e., demand functions as well as cost functions are non-linear. One of the important results of the analyses is that a reduction in a developed country's tariff can increase the world welfare as a whole in the case of decreasing marginal cost.
\end{abstract}

\section{Introduction}

Oligopolistic industries play a very important part in the world trade today. For example, almost $75 \%$ of value of Japanese export are made up of machinery and equipment products such as automobiles, electronic parts, computers, VTR, and communication equipment, which are well known to be produced by oligopolistic industries. These industries export their products not only to the market where their native rival companies are operating but also to the markets where there are no rival companies. They respond very swiftly to any change in their markets caused by an alteration of tariffs or subsidies. These kinds of changes cause some changes in trade volume as well as national welfare of each country. In this respect, a proper analysis of the effects of a change in one of the tariffs or subsidies on trade and welfare of each country must consider three countries. One is the country where an oligopolist produces and exports his product, one is the country where the oligopolist's rival company produces and exports her product, and the other is the country with no oligopolists resident there and imports oligopolistic good from the other countries.

In this paper we have constructed and analyzed the nature of the three-country trade model that seems to be fit to analyze the present world trade. This three-country trade model is especially suitable for the country whose imperfectly competitive product is exported to the developing countries who are not producing it now, as well as to the developed countries who produce the same good. So the model is the fittest for countries like US, EC, Japan, and some other OECD countries who have to consider the effects of trade barrier problems not only

Received 28 June; accepted in revised form 16 September 1999 
Hisayuki Okamoto : Pareto Improving Tariff Reduction Scheme in an Imperfectly Competitive Model of Trade: A Three-Country Case

on the other industrialized nations but also on the developing nations.

Recently many economists have been studying the international trade theory with imperfect competition. Studies of Brander (1981), Brander and Krugman (1983), Brander and Spencer (1984a, b), Cheng (1988), Dixit (1984, 1988), Eaton and Grossman (1984), Gatsios (1990), Krugman (1984), Uekawa (1990), and many other economists have made valuable contributions to this theory. However, all these models except Gatsios (1990) are based on a two-country framework. And except for a few works such as Krugman (1984), Okamoto (1998), and Uekawa (1990), they have assumed marginal costs to be constant. The purpose of the current paper is to enlarge the above analyses in two directions: one is to three-country framework and the other is to non-linear technology framework.

There are very few works on the international trade theory of imperfect competition with non-constant marginal cost. As will be demonstrated below, the constant marginal cost case is very restrictive and often leads to spotlighting a special cases too much. Therefore, to investigate properly the theory of imperfect competition account needs to be taken of the non-constant marginal cost case. Actually some of the comparative static results are very sensitive to the nature of marginal cost. (To understand this see also Okamoto and Yoshida (1994) which assumes increasing marginal cost.)

In this paper we investigate the following questions by assuming that each duopolist's marginal cost is nonincreasing (opposite to the Okamoto-Yoshida model): (1) Under what conditions the uniqueness of the solution will be assured? (2) How will a change in tariff rate of each country affect the outputs of the two industrialized countries? (3) Is it possible that a reduction in one of the countries' tariff rates improves the world welfare? (4) What kind of tariff reduction scheme will be a Pareto improving for the world as a whole?

The remainder of this paper is organized as follows. The next section presents a three-country trade model and its assumptions. Section 3 provides an examination of the Cournot equilibrium condition of the model and examines the effect of a change in tariff rates on each firm's supplies and the consumption of each country. Section 4 examines the world welfare effects of a tariff reduction. The last section provides some concluding remarks.

\section{The Model and the Assumptions}

In this section we develop the framework of the three-country trade model and explain its basic assumptions.

\subsection{The framework of the model}

We develop a three-country, two-commodity model of international trade with intra-industry trade of identical manufactured good between industrialized countries. Let the world consist of three countries as in Figure 1: two industrialized countries called country $\mathrm{H}$ and country F, and a developing country called country I. A perfectly competitive good $\mathrm{V}$, which is taken as the numeraire, is produced in every country ${ }^{(1)}$. In the two industrialized countries, another homogeneous commodity $\mathrm{M}$ is produced under imperfectly competitive situations by two firms: one is duopolist $\mathrm{H}$ in country $\mathrm{H}$ and the other is duopolist $\mathrm{F}$ in country $\mathrm{F}$. This imperfectly competitive good is traded between the two developed countries and the third developing country. Each duopolist is assumed to follow the Cournot competitive behavior in every market. 
Figure 1 The Three-Country Model of Trade

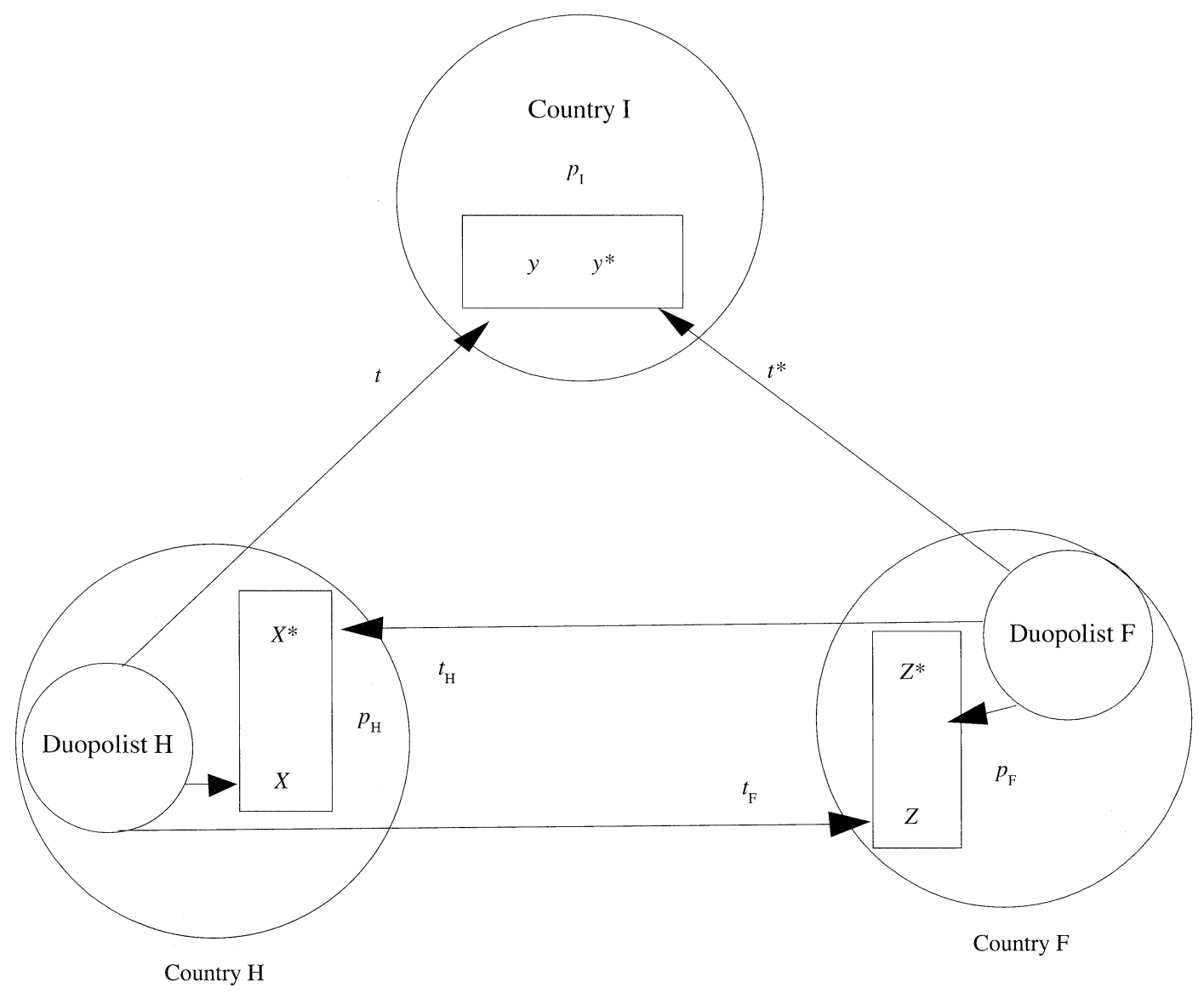

Let the production costs of the imperfectly competitive good be expressed by

$$
C(x+y+z) ; C^{*}\left(z^{*}+y^{*}+x^{*}\right),
$$

where $x\left(z^{*}\right), y\left(y^{*}\right)$, and $z\left(x^{*}\right)$ represents sales to duopolist H's (F's) home market, to the market in country I, and to the other duopolist's domestic market, respectively. Accordingly, $x+y+z\left(z^{*}+y^{*}+x^{*}\right)$ denotes total output of commodity M by duopolist H (duopolist F). Starred quantities are sometimes used for denoting the corresponding entities in country F. Let the cost functions have the following properties:

(1) $C^{\prime}>0, C^{\prime \prime} \leqq 0 ; C^{*}>0, C^{* \prime \prime} \leqq 0$.

That is, each duopolist's marginal cost is positive and non-increasing. Thus, both manufacturers have an incentive to expand the production of good $\mathrm{M}$.

The social utility function of each country is represented by

(2) $U_{\mathrm{H}}\left(X, V_{\mathrm{H}}\right) \equiv u_{\mathrm{H}}(X)+V_{\mathrm{H}} ; U_{\mathrm{I}}\left(Y, V_{\mathrm{I}}\right) \equiv u_{\mathrm{I}}(Y)+V_{\mathrm{I}} ; U_{\mathrm{F}}\left(Z, V_{\mathrm{F}}\right) \equiv u_{\mathrm{F}}(Z)+V_{\mathrm{F}}$, where $X \equiv x+x^{*}, Y \equiv y+y^{*}$, and $Z \equiv z+z^{*}$ denote the consumption of imperfectly good M in countries $\mathrm{H}$, I, and F, respectively: $V_{\mathrm{H}}, V_{\mathrm{I}}$, and $V_{\mathrm{F}}$ represent that of numeraire good $\mathrm{V}$ in countries $\mathrm{H}$, I, and F, respectively. We assume that $u_{i}(\cdot)(i=\mathrm{H}, \mathrm{I}, \mathrm{F})$ is strictly concave to the origin. Thus 
Hisayuki Okamoto : Pareto Improving Tariff Reduction Scheme in an Imperfectly Competitive Model of Trade: A Three-Country Case

(3) $u_{i}^{\prime}>0, \quad u_{i}^{\prime \prime}<0$, for $i=\mathrm{H}, \mathrm{I}, \mathrm{F}$.

This means that marginal utility of good $\mathrm{M}$ is positive and decreasing. Since utility function (2) implies the marginal utility of income equals 1 , the inverse demand function of good $\mathrm{M}$ in country $\mathrm{i}$ is just the derivative of $u_{i}$ :

(4) $p_{i}(\cdot)=u_{i}^{\prime}(\cdot)>0, p_{i}^{\prime}(\cdot)=u_{i}^{\prime \prime}(\cdot)<0$, for $i=\mathrm{H}, \mathrm{I}, \mathrm{F}$.

where $p_{i}(\cdot)$ represents the price of this good in country $\mathrm{i}$. Thus, in this model, each country's price of the imperfectly competitive commodity is positive and the demand curve of this good negatively sloped.

The trade policy instruments consist of the developing country's import tariffs (they may be negative), which can be discriminatory levied on the import of good $\mathrm{M}$ from countries $\mathrm{H}$ and $\mathrm{F}$, and each industrialized country's import tariff. Let country I's import tariff imposed on country H's products by $t$ and that on country F's products by $t^{*}$, while country H's import tariff on good $\mathrm{M}$ is $t_{\mathrm{H}}$ and country F's import tariff on commodity $\mathrm{M} t_{\mathrm{F}}$. Hence, profits of the two oligopolists are represented by

(5.1) $\pi\left(x, y, z, z^{*}, y^{*}, x^{*}\right) \equiv x p_{\mathrm{H}}(X)+y p_{\mathrm{I}}(Y)+z p_{\mathrm{F}}(Z)-C(Q)-t y-t_{\mathrm{F}} z$,

(5.2) $\quad \pi *\left(x, y, z, z^{*}, y^{*}, x^{*}\right) \equiv z^{*} p_{\mathrm{F}}(Z)+y^{*} p_{\mathrm{I}}(Y)+x^{*} p_{\mathrm{H}}(X)-C^{*}\left(Q^{*}\right)-t^{*} y^{*}-t_{\mathrm{H}} x^{*}$,

where $Q \equiv x+y+z$ and $Q^{*} \equiv z^{*}+y^{*}+x^{*}$, that is $Q$ and $Q^{*}$ denote the total production of good $\mathrm{M}$ in duopolist $\mathrm{H}$ and duopolist $\mathrm{F}$, respectively.

\subsection{Basic assumptions and equilibrium conditions}

In the ensuing analyses we shall assume the following conditions to be satisfied for all non-negative values of $x, y, z, z^{*}, y^{*}$, and $x^{*}$ in which the analyses are made.

$$
\begin{aligned}
& \text { C.1: } x p_{\mathrm{H}}{ }^{\prime}+p_{\mathrm{H}} \geqq 0, h_{\mathrm{H}} \equiv x p_{\mathrm{H}}{ }^{\prime \prime}+p_{\mathrm{H}}{ }^{\prime} \leqq 0 ; x^{*} p_{\mathrm{H}}{ }^{\prime}+p_{\mathrm{H}} \geqq 0, h_{\mathrm{H}}{ }^{*} \equiv x^{*} p_{\mathrm{H}}{ }^{\prime \prime}+p_{\mathrm{H}}{ }^{\prime} \leqq 0 ; \\
& y p_{\mathrm{I}}^{\prime}+p_{\mathrm{I}} \geqq 0, h_{\mathrm{I}} \equiv y p_{\mathrm{I}}^{\prime \prime}+p_{\mathrm{I}}{ }^{\prime} \leqq 0 ; y^{*} p_{\mathrm{I}}{ }^{\prime}+p_{\mathrm{I}} \geqq 0, h_{\mathrm{I}}^{*} \equiv y^{*} p_{\mathrm{I}}{ }^{\prime \prime}+p_{\mathrm{I}}{ }^{\prime} \leqq 0 ; \\
& z p_{\mathrm{F}}{ }^{\prime}+p_{\mathrm{F}} \geqq 0, h_{\mathrm{F}} \equiv z p_{\mathrm{F}}{ }^{\prime \prime}+p_{\mathrm{F}}{ }^{\prime} \leqq 0 ; z^{*} p_{\mathrm{F}}{ }^{\prime}+p_{\mathrm{F}} \geqq 0, h_{\mathrm{F}} * \equiv z^{*} p_{\mathrm{F}}{ }^{\prime \prime}+p_{\mathrm{F}}{ }^{\prime} \leqq 0 .
\end{aligned}
$$

C.2: $\quad C^{\prime}>0, C^{\prime \prime} \leqq 0 ; C^{* \prime}>0, C^{* \prime \prime} \leqq 0$.

C.3: $p_{\mathrm{H}}{ }^{\prime}-3 C^{\prime \prime}<0, p_{\mathrm{I}}^{\prime}-3 C^{\prime \prime}<0, p_{\mathrm{F}}{ }^{\prime}-3 C^{\prime \prime}<0$;

$p_{\mathrm{H}}{ }^{\prime}-3 C^{* \prime \prime}<0, p_{\mathrm{I}}^{\prime}-3 C^{* \prime \prime}<0, p_{\mathrm{F}}^{\prime}-3 C^{* \prime \prime}<0$.

C.4: $h_{\mathrm{H}}+p_{\mathrm{H}}{ }^{\prime}-3 C^{\prime \prime}<h_{\mathrm{H}}^{*}, h_{\mathrm{I}}+p_{\mathrm{I}}{ }^{\prime}-3 C^{\prime \prime}<h_{\mathrm{I}}^{*}, h_{\mathrm{F}}+p_{\mathrm{F}}{ }^{\prime}-3 C^{\prime \prime}<h_{\mathrm{F}} * ;$

$h_{\mathrm{H}}^{*}+p_{\mathrm{H}}{ }^{\prime}-3 C^{* \prime \prime}<h_{\mathrm{H}}, h_{\mathrm{I}}^{*}+p_{\mathrm{I}}^{\prime}-3 C^{* \prime \prime}<h_{\mathrm{l}}, h_{\mathrm{F}}{ }^{*}+p_{\mathrm{F}}{ }^{\prime}-3 C^{* \prime \prime}<h_{\mathrm{F}}$.

First, C.1 requires that each duopolist's marginal revenue in every market is non-negative and satisfies the Hahn (1962) stability condition combined with the negative slopedness of each demand function. Second, C.2 demands every firm's average cost and marginal cost are decreasing and (weakly) convex to the origin, and which means that each duopolist has an incentive to expand his production. Third, C.3 requests that the inverse demand function of each market is steep and/or each manufacturer's marginal cost curve is flat. Finally, in view of C. 3 and the definitions of $h_{i}$ 's and $h_{i}{ }^{*}$ 's, C.4 asks the absolute values of $p_{i}{ }^{\prime \prime}(i=\mathrm{H}, \mathrm{I}, \mathrm{F}$ ) are not to be too large. That is, the inverse demand curve of each market can be concave and/or convex to the origin but the degree of concavity and/or convexity should be restricted.

In the above assumptions, C. 3 and C. 4 are somewhat restrictive ones. When the stability conditions of each market are considered separately, it is suffice to assume the Hahn stability condition. But when the stability of 
all the segmented markets simultaneously, some additional conditions such as C.3 and C.4 are needed. In this respect, what Okuguchi (1990a, b) assumed in his Cournot duopoly model with several markets are somewhat similar to the present model.

Under the Cournot assumption on each firm's behavior in every market, the first order conditions for profit maximization are:

$$
\begin{aligned}
& \text { (6.1) } x p_{\mathrm{H}}{ }^{\prime}(X)+p_{\mathrm{H}}(X)-C^{\prime}(Q)=0, \\
& \text { (6.2) } y p_{\mathrm{I}}^{\prime}(Y)+p_{\mathrm{I}}(Y)-C^{\prime}(Q)=t, \\
& \text { (6.3) } z p_{\mathrm{F}}^{\prime}(Z)+p_{\mathrm{F}}(Z)-C^{\prime}(Q)=t_{\mathrm{F}}, \\
& \text { (6.4) } z^{*} p_{\mathrm{F}}^{\prime}(Z)+p_{\mathrm{F}}(Z)-C^{* \prime}\left(Q^{*}\right)=0, \\
& \text { (6.5) } y^{*} p_{\mathrm{I}}^{\prime}(Y)+p_{\mathrm{I}}(Y)-C^{* \prime}\left(Q^{*}\right)=t^{*}, \\
& \text { (6.6) } x^{*} p_{\mathrm{H}}(X)+p_{\mathrm{H}}(X)-C^{* \prime}\left(Q^{*}\right)=t_{\mathrm{H}} .
\end{aligned}
$$

In this context, $x, y, z, z^{*}, y^{*}$, and $x^{*}$ are the endogenous variables and $t, t_{\mathrm{F}}, t^{*}$, and $t_{\mathrm{H}}$ are exogenous variables of the model. Given the values of the exogenous variables, the values of the endogenous variables are supposed to be determined. In the following sections we shall investigate the nature of the above equation system (6), and the effects of changes in tariff rates on the supply of the good M to each market and the welfare of each country.

\section{The Analysis}

In this section we shall examine the effects of change in tariff rates on the endogenous variables. First we shall investigate the uniqueness of the comparative static equation system of tariff change. Then we shall proceed to the comparative static analysis.

\subsection{The uniqueness of the solution}

Now, let us consider changes in policy instruments $t, t_{\mathrm{F}}, t^{*}$, and $t_{\mathrm{H}}$ on the Cournot equilibrium. Totally differentiating (6), we obtain the following equation system for comparative static analysis.

$$
\left[\begin{array}{ccc}
\mathrm{a}_{11} & \cdots & \mathrm{a}_{16} \\
\cdot & & \cdot \\
\cdot & & \cdot \\
\cdot & & \cdot \\
\cdot & & \cdot \\
\mathrm{a}_{61} & \cdots & \mathrm{a}_{66}
\end{array}\right]\left[\begin{array}{c}
d x^{*} \\
d y \\
d z \\
d z^{*} \\
d y^{*} \\
d x^{*}
\end{array}\right]=\left[\begin{array}{c}
0 \\
d t \\
d t_{\mathrm{F}} \\
0 \\
d t^{*} \\
d t_{\mathrm{H}}
\end{array}\right]
$$

where $\left(a_{i j}\right) \equiv A$ is represented as follows:

$$
A \equiv\left[\begin{array}{cccccc}
h_{\mathrm{H}}+p_{\mathrm{H}}{ }^{\prime}-C^{\prime \prime} & -C^{\prime \prime} & -C^{\prime \prime} & 0 & 0 & h_{\mathrm{H}} \\
-C^{\prime \prime} & h_{\mathrm{I}}+p_{\mathrm{I}}{ }^{\prime}-C^{\prime \prime} & -C^{\prime \prime} & 0 & h_{\mathrm{I}} & 0 \\
-C^{\prime \prime} & -C^{\prime \prime} & h_{\mathrm{F}}+p_{\mathrm{F}}{ }^{\prime}-C^{\prime \prime} & h_{\mathrm{F}} & 0 & 0 \\
0 & 0 & h_{\mathrm{F}}{ }^{*} & h_{\mathrm{F}}{ }^{*}+p_{\mathrm{F}}{ }^{\prime}-C^{* \prime \prime} & -C^{* \prime \prime} & -C^{* \prime \prime} \\
0 & h_{\mathrm{I}}^{*} & 0 & -C^{* \prime} & h_{\mathrm{I}}^{*}+p_{\mathrm{I}}{ }^{\prime}-C^{* \prime \prime} & -C^{* \prime \prime} \\
h_{\mathrm{H}}^{*} & 0 & 0 & -C^{* \prime \prime} & -C^{* \prime \prime} & h_{\mathrm{H}}{ }^{*}+p_{\mathrm{H}}{ }^{\prime}-C^{* \prime \prime}
\end{array}\right]
$$


The above matrix $\mathrm{A}$ is the Jacobian matrix of the equation system (6). Let us investigate the nature of this matrix. First, from Assumptions C.1 and C.3, all the diagonal elements of $A$ are strictly negative. Second, under Assumptions C.1 through C.4, these diagonal elements are dominant elements in every column. Thus, under Assumptions C.1 through C.4, the matrix $A$ is a matrix with negative dominant diagonals ${ }^{(2)}$, and so all the principal minors of A with order 5 and 3 are negative and those with 6,4 , and 2 positive. Therefore, we see that the Jacobian matrix A is an N-P matrix ${ }^{(3)}$, so that the solution to the equation system (6) must be unique ${ }^{(4)}$. Thus we have established the following important proposition.

Theorem 1: The Jacobian matrix A of the Cournot equilibrium conditions of the model is an N-P matrix under Assumptions C.1 through C.4. Hence, the Cournot equilibrium solution of the model is unique. (For the proof of this, see Nikaido (1968, p.371).)

Note that this theorem assures the uniqueness of the Cournot equilibrium solution if there exists a solution to the equation system (6). The problem about the existence of a solution in a Cournot competitive oligopoly model with several markets under virtually the same assumptions of ours was proved by Okuguchi (1990a, b) (5). He also proved the stability of the solution under the same assumptions. Thus, we can safely conduct the comparative static analysis of the equation system (6) under Assumptions C.1 through C.4.

Now, let us examine the comparative static results of changes in policy instruments on the production of each firm and the consumption in each market. The results can be analyzed by the following equation:

$$
\left[\begin{array}{l}
d x \\
d y \\
d z \\
d z^{*} \\
d y^{*} \\
d x^{*}
\end{array}\right]=\operatorname{det}(A)^{-1}\left[\begin{array}{cccccc}
A_{11} & A_{21} & A_{31} & A_{41} & A_{51} & A_{61} \\
A_{12} & A_{22} & A_{32} & A_{42} & A_{52} & A_{62} \\
A_{13} & A_{23} & A_{33} & A_{43} & A_{53} & A_{63} \\
A_{14} & A_{24} & A_{34} & A_{44} & A_{54} & A_{64} \\
A_{15} & A_{25} & A_{35} & A_{45} & A_{55} & A_{65} \\
A_{16} & A_{26} & A_{36} & A_{46} & A_{56} & A_{66}
\end{array}\right]\left[\begin{array}{c}
0 \\
d t \\
d t_{\mathrm{F}} \\
0 \\
d t^{*} \\
d t_{\mathrm{H}}
\end{array}\right]
$$

Where $\operatorname{det}(A)$ and $A_{i j}$ denote the determinant of matrix $A$ and the cofactor the $(i, j)$ th element in $A$. In the following sections let us consider the nature of this solution.

\subsection{The effects of a change in $t$ and $t^{*}$}

In this sub-section, we shall investigate the effects of a change in $t$ and $t^{*}$ on production of good $\mathrm{M}$ in each firm and consumption in every country. Let us consider the effects of a change in $t$ first. From (8) we obtain the following equations:
(9.1) $\partial x / \partial t \equiv x_{1}=A_{21} / \operatorname{det}(A) \leqq 0$,
(9.2) $\partial y / \partial t \equiv y_{1}=A_{22} / \operatorname{det}(A)<0$,
(9.3) $\partial z / \partial t \equiv z_{1}=A_{23} / \operatorname{det}(A) \leqq 0$,
(9.4) $\partial z * / \partial t \equiv z^{*}=A_{24} / \operatorname{det}(A) \geqq 0$,
(9.5) $\partial y^{*} / \partial t \equiv y^{*}=A_{25} / \operatorname{det}(A) \geqq 0$
(9.6) $\partial x * / \partial t \equiv x^{*}{ }_{1}=A_{26} / \operatorname{det}(A) \geqq 0$

where the equalities hold if $C^{\prime \prime}=C^{* \prime}=0$ except (9.5). $A_{25}=0$ holds if $C^{\prime \prime}=h_{1}^{*}=0$. (The signs of the above 
equations are derived in the Appendix A.1.1. ${ }^{(6)}$ )

Let us examine the expressions just obtained. First, from (9.2) and (9.5), we see that a rise in $t$ necessarily reduces duopolist H's export to country I, whereas it increases duopolist F's export to country I. But in the framework of this model, as it can easily be imagined, the former effect dominates the latter. As a matter of fact, we have

(9.7) $\partial Y / \partial t=y_{1}+y_{1}^{*}=\left(A_{22}+A_{25}\right) / \operatorname{det}(A)<0$.

Thus, if the government of country I tightens its restriction on import of good $\mathrm{M}$ from one of the industrialized countries, it results in the reduction of domestic consumption of country I.

Second, from (9.1)-(9.6), a rise in $t$ causes some changes in each firm's supply to its home market and the volume of intra-industry trade. Duopolist $\mathrm{H}$, whose tariff rate is increased and so the net marginal revenue (=marginal revenue - marginal increase in tariff payment) is deteriorated, reduces its total production $(\partial Q / \partial t<$ 0 ) and its supplies to every market. On the contrary, duopolist F, whose relative position in the international competition is improved, increases its total production $\left(\partial Q^{*} \partial t>0\right)$ and its supply to each market. Because a reduction in supply of good $\mathrm{M}$ from duopolist $\mathrm{H}$ causes a rise in price of good $\mathrm{M}$ in each market, which in turn causes an upward shift in the net marginal revenue of duopolist F. By these changes in each duopolist's supply to each market, total volume of commodity $\mathrm{M}$ to the each market and the volume of intra-industry trade may increase or decrease depending on the cost conditions of each firm. But careful calculation leads to the following results:

(9.8) $\partial X / \partial t=\partial\left(x+x^{*}\right) / \partial t=\left(h_{\mathrm{F}}+h_{\mathrm{F}}{ }^{*}+h_{\mathrm{F}}{ }^{\prime}\right) \varepsilon_{\mathrm{I}}<0 \quad$ iff $\quad \varepsilon_{\mathrm{I}}>0$,

(9.9) $\partial Z / \partial t=\partial\left(z+z^{*}\right) / \partial t=\left(h_{\mathrm{H}}+h_{\mathrm{H}}{ }^{*}+P_{\mathrm{H}}{ }^{\prime}\right) \varepsilon_{\mathrm{I}}<0 \quad$ iff $\quad \varepsilon_{\mathrm{I}}>0$,

(9.10) $\partial I T / \partial t=\partial\left(z+x^{*}\right) / \partial t=\left(A_{23}+A_{26}\right) / \operatorname{det}(A) \leqq 0$,

where $\varepsilon_{\mathrm{I}} \equiv h_{\mathrm{I}}{ }^{*} p_{\mathrm{F}}{ }^{\prime} p_{\mathrm{H}}{ }^{\prime}\left(C^{\prime \prime}-C^{* \prime \prime}\right)+p_{\mathrm{H}}{ }^{\prime} p_{\mathrm{I}}^{\prime} p_{\mathrm{F}}{ }^{\prime} C^{\prime \prime}-\left(p_{\mathrm{H}}{ }^{\prime} p_{\mathrm{I}}{ }^{\prime}+p_{\mathrm{I}}{ }^{\prime} p_{\mathrm{F}}{ }^{\prime}+p_{\mathrm{F}}{ }^{\prime} p_{\mathrm{H}}{ }^{\prime}\right) C^{\prime \prime} C^{* \prime \prime}$ and $I T$ denotes the volume of intra-industry trade. (For the proof, see Appendix A.1.1.) From above expressions, we see that intraindustrial trade between two industrialized countries reduces by a rise in $t$, while total supplies of good $\mathrm{M}$ in countries $\mathrm{H}$ and $\mathrm{F}$ depend on the sign of $\varepsilon_{\mathrm{I}}$. In the above expression, condition $\varepsilon_{\mathrm{I}}>0$ needs explanation. Let us consider the intuitive economic meaning of this condition.

In order to consider this problem, it is needed to take into account the marginal cost curve and net marginal revenue curve. But neglecting some differences in net marginal revenue curve for the moment, let us consider the slope of marginal cost curve. Note that if we assume standard $U$ shaped average cost curve, marginal cost curve is also U shaped, and so $C^{\prime \prime}\left(Q_{1}\right)<C^{\prime \prime}\left(Q_{2}\right) \leqq 0$ means $C^{\prime}\left(Q_{1}\right)>C^{\prime}\left(Q_{2}\right)$, i.e., production of $Q_{1}$ takes place at the steeper part of marginal cost curve than that of $Q_{2}$. Then, by the simple graphical consideration, a shift in net marginal cost curve at $Q_{2}$ tends to produce less production shift than at $Q_{1}$. Thus, it is quite simple to compare the change in production volume caused by a tariff rise and ensuing upward shift in net marginal revenue curve, if the two marginal cost curves are the same.

The comparison becomes complicated when the two marginal cost curves and the two net marginal revenue curves are different. However, intuitively speaking, we can still conclude that if $C^{\prime \prime} \leqq C^{* \prime} \leqq 0$, then a rise in 
Figure 2 The Region Satisfying $\varepsilon_{\mathrm{I}}>0$

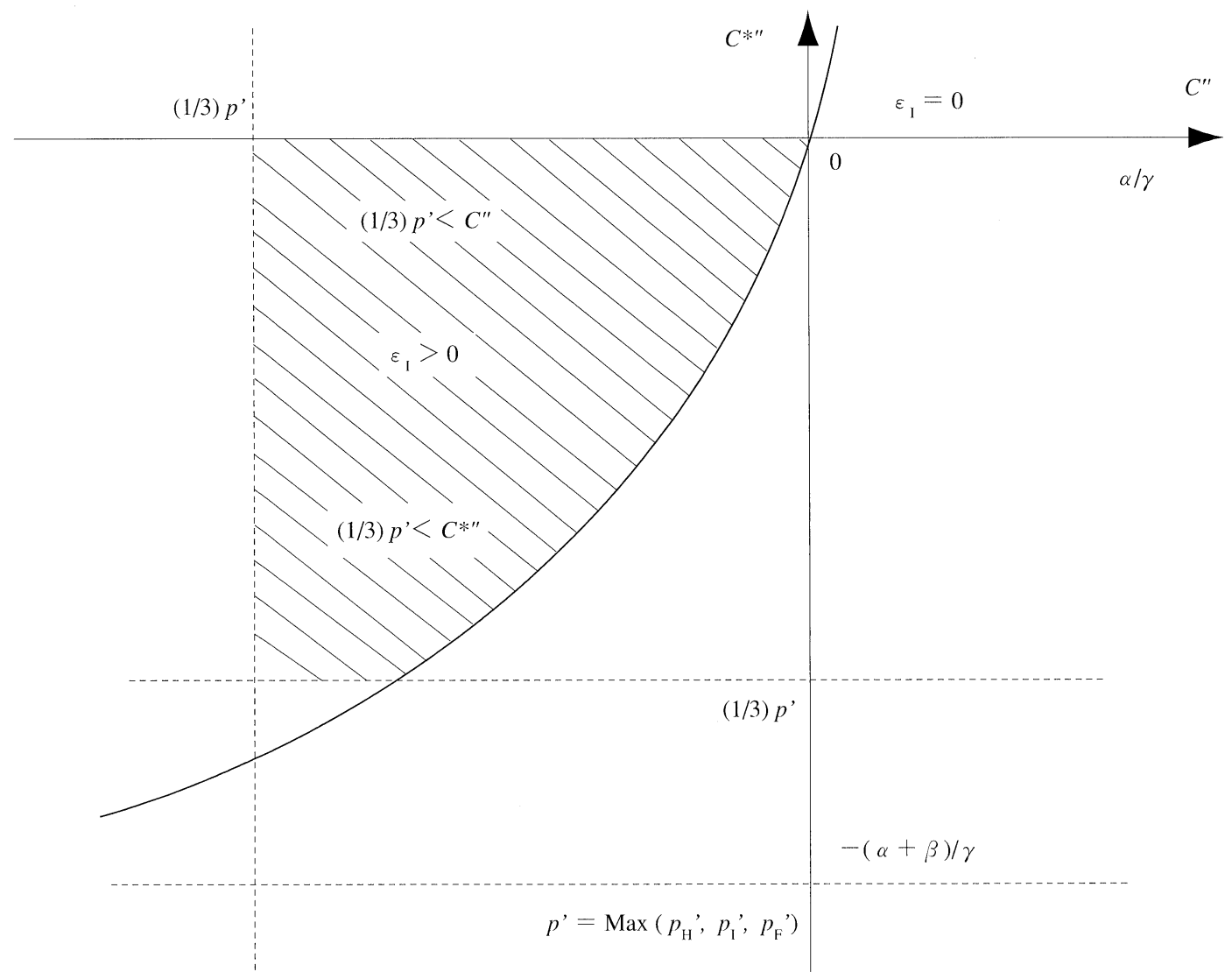

tariff rate $t$ will cause a reduction in world total production of good M. As a matter of fact, when $C^{\prime \prime}=C^{* \prime \prime}$ then

$$
\varepsilon_{\mathrm{I}}=(1 / 3) C^{\prime \prime}\left[p_{\mathrm{H}} p_{\mathrm{I}}^{\prime}\left(p_{\mathrm{F}}{ }^{\prime}-3 C^{* \prime \prime}\right)+p_{\mathrm{I}}{ }^{\prime} p_{\mathrm{I}}{ }^{\prime}\left(p_{\mathrm{F}}{ }^{\prime}-3 C^{* \prime \prime}\right)+p_{\mathrm{F}}{ }^{\prime} p_{\mathrm{H}}{ }^{\prime}\left(p_{\mathrm{F}}{ }^{\prime}-3 C^{* \prime \prime}\right)\right] \geqq 0
$$

where the equality holds only if $C^{\prime \prime}=C^{* \prime}=0$. If $C^{\prime \prime}<C^{* \prime \prime} \leqq 0$ then $\varepsilon_{\mathrm{I}}>0$ a fortiori. In this case, from (9.8) and (9.9), total supply of good M decreases if $t$ is raised. Thus $\varepsilon_{\mathrm{I}}>0$ is the (necessary and sufficient) condition for the world total production of good $\mathrm{M}$ being reduced caused by a rise in $t$.

The condition $\varepsilon_{\mathrm{I}}>0$ is illustrated in Figure 2. In this figure the pair ( $C^{\prime \prime}, C^{* \prime \prime}$ ) which satisfies condition $\varepsilon_{\mathrm{I}}$ $>0$ as well as C.1 through C.4 is shown by the shaded area ${ }^{(7)}$. Note that if $0 \geqq C^{\prime \prime}>C^{* \prime \prime}$ then $\varepsilon_{1}$ can be nonpositive. From Figure 2, there remains a plenty of region this can occur under Assumptions C.1 through C.4. Thus, from (9.8) and (9.9), $X$ and $Z$ can be increased as a result of a rise in $t$. Hence, we have established the following theorem.

Theorem 2: An increase in country I's import tariff rate t necessarily reduces consumption of imperfectly competitive good $M$ in country I and intra-industry trade between the two industrialized countries as well as total production of duopolist $H$, whereas it increases the other duopolist's total production. On the other hand, it reduces consumption of good $M$ in countries $H$ and $F$ if and only if $\varepsilon_{I}>0$.

Now let us examine the effects of a change in $t^{*}$. From the structure of the model, similar symmetric results 
Figure 3 The Region Satisfying $\varepsilon_{\mathrm{I}}>0$ and $\varepsilon_{\mathrm{I}}^{*}>0$

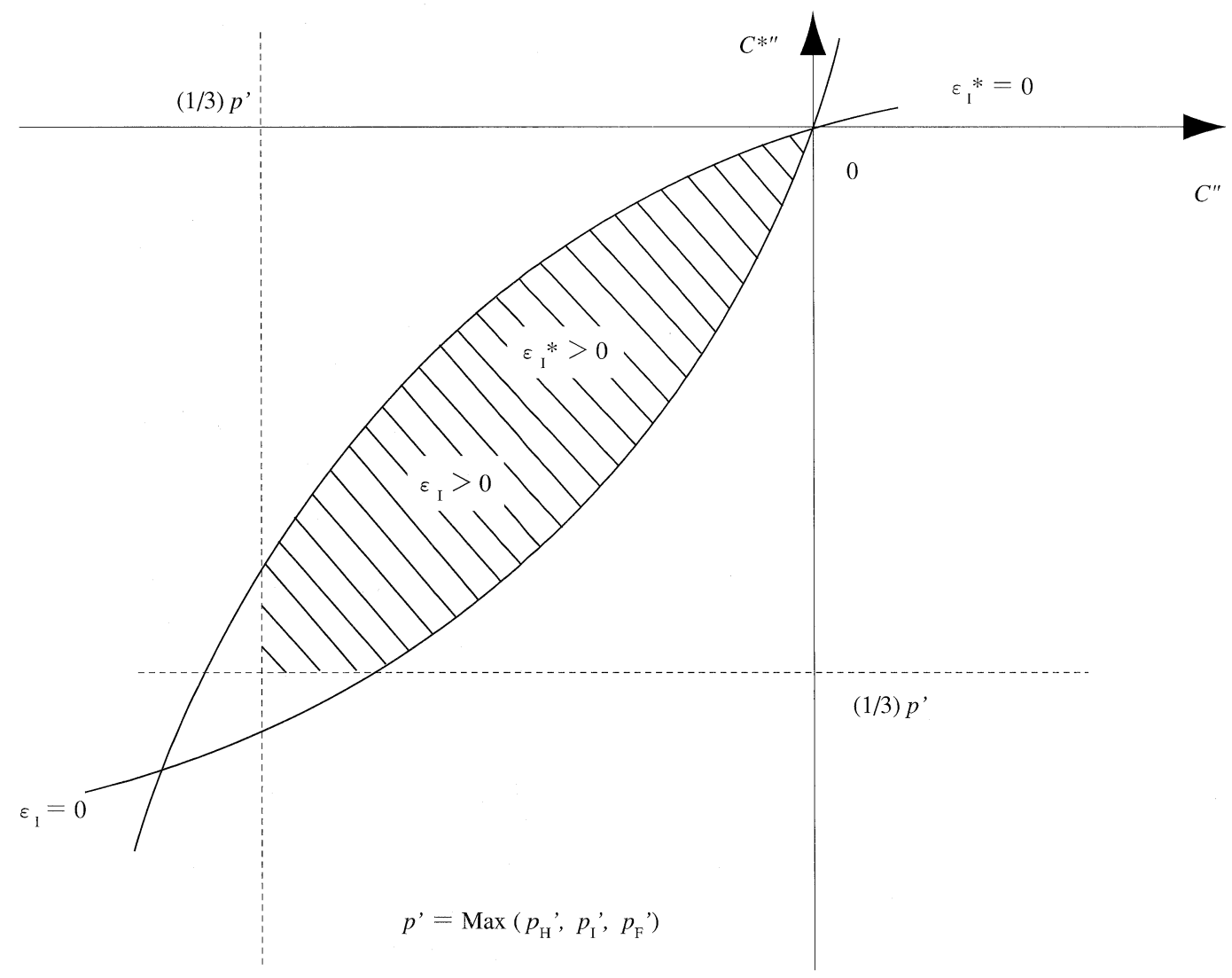

are obtained. As a matter of fact, if we define

$$
\varepsilon_{\mathrm{I}}^{*} \equiv h_{\mathrm{I}} p_{\mathrm{F}}{ }^{\prime} p_{\mathrm{H}}{ }^{\prime}\left(C^{* \prime \prime}-C^{\prime \prime}\right)+p_{\mathrm{H}}^{\prime} p_{\mathrm{I}}^{\prime} p_{\mathrm{F}} C^{* \prime \prime}-\left(p_{\mathrm{H}}^{\prime} p_{\mathrm{I}}{ }^{\prime}+p_{\mathrm{I}}^{\prime} p_{\mathrm{F}}{ }^{\prime}+p_{\mathrm{F}}{ }^{\prime} p_{\mathrm{H}}{ }^{\prime}\right) C^{\prime \prime} C^{* \prime}
$$

then we can establish the following corollary:

Corollary 2.1: An increase in country I's import tariff rate $t^{*}$ necessarily reduces consumption of imperfectly competitive good $M$ in country I and intra-industry trade between the two industrial countries and as well as total production of duopolist $F$, whereas it increases the other duopolist's total production. On the other hand, it reduces consumption of good $M$ in countries $H$ and $F$ if and only if $\varepsilon_{I^{*}}>0$.

Remark: Note that the conditions $\varepsilon_{I^{*}}>0$ and $\varepsilon_{\mathrm{I}}>0$ can coexist. In Figure 3 , the shaded area denotes the pair $\left(C^{\prime \prime}, C^{* \prime \prime}\right)$ which satisfies conditions $\varepsilon_{\mathrm{I}}>0$ and $\varepsilon_{\mathrm{I}}>0$ as well as Assumptions C.1 through C.3. Because the set $\left\{\left(C^{\prime \prime}, C^{* \prime \prime}\right): \varepsilon_{\mathrm{I}}>0\right.$ and $\varepsilon_{\mathrm{I}}^{*}>0$ for $C^{\prime \prime}<0$ and $C^{* \prime \prime}<0$ and satisfy C.1-C.3 $\}$ is not empty, the shaded region does exist. (For the proof, see Appendix A.4.) Thus, the results of Theorem 2 and Corollary 2.1 can coexist. Especially, when $C^{\prime \prime}$ and $C^{* \prime}$ are in this set, an increase in any one of country I's import tariff rates decreases consumption of good $\mathrm{M}$ in both industrialized countries.

\subsection{The effects of a change in $t_{\mathrm{F}}$ and $t_{\mathrm{H}}$}

First let us investigate the effects of a change in $t_{\mathrm{F}}$ on production of good $\mathrm{M}$ in each firm and consumption in 
every country. From (8) we obtain the following equations:

$$
\begin{array}{ll}
(10.1) & \partial x / \partial t_{\mathrm{F}} \equiv x_{2}=A_{31} / \operatorname{det}(A) \leqq 0, \\
(10.2) & \partial y / \partial t_{\mathrm{F}} \equiv y_{2}=A_{32} / \operatorname{det}(A) \leqq 0, \\
(10.3) & \partial z / \partial t_{\mathrm{F}} \equiv z_{2}=A_{31} / \operatorname{det}(A)<0, \\
(10.4) & \partial z * / \partial t_{\mathrm{F}} \equiv z_{2}=A_{34} / \operatorname{det}(A) \geqq 0, \\
(10.5) & \partial y * / \partial t_{\mathrm{F}} \equiv *_{2}=A_{35} / \operatorname{det}(A) \geqq 0, \\
(10.6) & \partial x * / \partial t_{\mathrm{F}} \equiv *_{2}=A_{36} / \operatorname{det}(A) \geqq 0,
\end{array}
$$

where the equalities hold if $C^{\prime \prime}=C^{* \prime \prime}=0$ except (10.6). $A_{36}=0$ holds if $C^{* \prime \prime}=h_{\mathrm{I}}=0$.

First, from (10.3) and (10.6), we see that a rise in $t_{\mathrm{F}}$ necessarily reduces duopolist H's export to country F, whereas it increases duopolist F's export to country H. But in the framework of this model, as it can easily be imagined, the former effect dominates the latter. As a matter of fact, we have

$$
\text { (10.7) } \partial I T / \partial t_{\mathrm{F}}=z_{2}+z_{2} *_{2}=\left(A_{33}+A_{36}\right) / \operatorname{det}(A)<0 .
$$

Thus, if the government of country F tightens its restriction on import of good $\mathrm{M}$ from country $\mathrm{H}$, it results in the reduction of intra-industry trade.

Second, from (10.1)-(10.6), duopolist $\mathrm{H}$, whose tariff rate is increased and so the net marginal revenue is deteriorated, reduces its total production $\left(\partial Q / \partial t_{\mathrm{F}}<0\right)$ and its supplies to every market. On the contrary, duopolist $\mathrm{F}$, whose relative position in the international competition is improved, increases its total production $(\partial Q * /$ $\partial t_{\mathrm{F}}>0$ ) and its supply to each market. Because a reduction in supply of good $\mathrm{M}$ from duopolist $\mathrm{H}$ causes a rise in price of good $\mathrm{M}$ in each market, which in turn causes an upward shift in the net marginal revenue of duopolist F. By these changes in each duopolist's supply to each market, total volume of commodity $\mathrm{M}$ to the each market increase or decrease depending on the cost conditions of each firm. But careful calculation leads to the following results:

$$
\begin{aligned}
& \text { (10.8) } \partial X / \partial t_{\mathrm{F}}=\partial\left(x+x^{*}\right) / \partial t_{\mathrm{F}}=\left(h_{\mathrm{I}}+h_{\mathrm{I}}^{*}+h_{\mathrm{I}}{ }^{\prime}\right) \varepsilon_{\mathrm{F}}<0 \quad \text { iff } \quad \varepsilon_{\mathrm{F}}>0, \\
& \text { (10.9) } \partial Y / \partial t_{\mathrm{F}}=\partial\left(y+y^{*}\right) / \partial t_{\mathrm{F}}=\left(h_{\mathrm{H}}+h_{\mathrm{H}}{ }^{*}+p_{\mathrm{H}}\right) \varepsilon_{\mathrm{F}}<0 \quad \text { iff } \quad \varepsilon_{\mathrm{F}}>0, \\
& \text { (10.10) } \partial Z / \partial t_{\mathrm{F}}=\partial\left(z+z^{*}\right) / \partial t_{\mathrm{F}}=\left(A_{23}+A_{24}\right) / \operatorname{det}(A)<0,
\end{aligned}
$$

where $\varepsilon_{\mathrm{F}} \equiv h_{\mathrm{F}}^{*} p_{\mathrm{H}}{ }^{\prime} p_{\mathrm{I}}{ }^{\prime}\left(C^{\prime \prime}-C^{* \prime \prime}\right)+p_{\mathrm{H}}{ }^{\prime} p_{\mathrm{I}}^{\prime} p_{\mathrm{F}} C^{\prime \prime}-\left(p_{\mathrm{H}}^{\prime} p_{\mathrm{I}}^{\prime}+p_{\mathrm{I}}{ }^{\prime} p p^{\prime}+p_{\mathrm{F}}{ }^{\prime} p p^{\prime}\right) C^{\prime \prime} C^{* \prime \prime}$. (For the proof see Appendix A.1.2.) From above expressions, we see that intra-industrial trade between two industrialized countries is reduced by a rise in $t_{\mathrm{F}}$, while the signs of changes in total supplies of good $\mathrm{M}$ in countries $\mathrm{H}$ and $\mathrm{F}$ depend on the sign of $\varepsilon_{\mathrm{F}}$. Consequently, we have established the following theorem:

Theorem 3: An increase in country F's import tariff rate tFnecessarily reduces consumption of good $M$ in country $F$ and total production of duopolist $H$ as well as intra-industry trade between countries $H$ and $F$, whereas it increases the total production of duopolist $F$. On the other hand, it reduces consumption of good $M$ in countries $H$ and I if and only if $\varepsilon_{F}>0$.

Remark: $\varepsilon_{\mathrm{F}}$ and $\varepsilon_{\mathrm{I}}$ have the same structure. The difference between them is

$$
\varepsilon_{\mathrm{I}}-\varepsilon_{\mathrm{F}}=p_{\mathrm{H}}{ }^{\prime} p_{\mathrm{I}}^{\prime} p_{\mathrm{F}}{ }^{\prime}\left(y^{*} p_{\mathrm{I}}^{\prime \prime} / p_{\mathrm{I}}^{\prime}-z^{*} p_{\mathrm{F}}^{\prime \prime} / p_{\mathrm{F}}{ }^{\prime}\right)\left(C^{\prime \prime}-C^{* \prime \prime}\right),
$$

where $y^{*} p_{\mathrm{I}}{ }^{\prime \prime} / p_{\mathrm{I}}{ }^{\prime}\left(z^{*} p_{\mathrm{F}}{ }^{\prime \prime} / p_{\mathrm{F}}{ }^{\prime}\right)$ represents the elasticity of the slope of the demand curve for duopolist $\mathrm{F}$ 's good in 
country I (country F). Therefore, if the two elasticities are not so different and/or the difference between $C^{\prime \prime}$ and $C^{* \prime}$ is small enough, the difference between $\varepsilon_{\mathrm{I}}$ and $\varepsilon_{\mathrm{F}}$ can be negligible. (For example, if the demand functions of the two countries are linear, the two elasticities are equal to zero and so $\varepsilon_{F}=\varepsilon_{I}$.) In this case, the results of Theorem 2 and Theorem 3 can coexist.

Next, let us examine the effects of a change in $t_{\mathrm{H}}$. From the structure of the model, similar symmetric results are obtained. As a matter of fact, if we define

$$
\varepsilon_{\mathrm{H}} \equiv h_{\mathrm{H}}^{*} p_{\mathrm{I}}^{\prime} p_{\mathrm{F}}^{\prime}\left(C^{* \prime \prime}-C^{\prime \prime}\right)+p_{\mathrm{H}}^{\prime} p_{\mathrm{I}}^{\prime} p_{\mathrm{F}}^{\prime} C^{* \prime \prime}-\left(p_{\mathrm{H}}{ }^{\prime} p_{\mathrm{I}}{ }^{\prime}+p_{\mathrm{I}}^{\prime} p_{\mathrm{F}}{ }^{\prime}+p_{\mathrm{F}}{ }^{\prime} p_{\mathrm{H}}{ }^{\prime}\right) C^{\prime \prime} C^{* \prime \prime}
$$

we can establish the following theorem:

Corollary 3.1: An increase in country $H$ 's import tariff rate tHnecessarily reduces consumption of good $M$ in the country and intra-industry trade between countries $H$ and $F$ as well as total production of duopolist $F$, whereas it increases the total production of duopolist $H$. On the other hand, it reduces consumption of good $M$ in countries $I$ and $H$ if and only if $\varepsilon_{H}>0$.

Note that if $\varepsilon_{\mathrm{I}} \fallingdotseq \varepsilon_{\mathrm{I}}^{*} \doteqdot \varepsilon_{\mathrm{H}} \doteqdot \varepsilon_{\mathrm{F}}$ then the results of Theorems 2 and 3 as well as Corollaries 2.1 and 3.1 can coexist. This condition is satisfied with equality, if the demand function of each country is linear or the marginal cost of each duopolist is constant.

\section{Welfare Effects of Tariff Change}

In this section, we shall investigate the welfare effects of a tariff reduction. Before proceeding to the investigation, let us define the social welfare function $S W_{i}(i=\mathrm{H}, \mathrm{I}, \mathrm{F})$ of each country as usual way:

$$
\begin{array}{ll}
\text { (11.1) } & S W_{\mathrm{H}}\left(t, t_{\mathrm{F}}, t^{*}, t_{\mathrm{H}}\right) \equiv u_{\mathrm{H}}(X)-X p_{\mathrm{H}}(X)+\pi+t_{\mathrm{H}} x^{*} \equiv C S_{\mathrm{H}}+\pi+t_{\mathrm{H}} x^{*}, \\
(11.2) & S W_{\mathrm{I}}\left(t, t_{\mathrm{F}}, t^{*}, t_{\mathrm{H}}\right) \equiv u_{\mathrm{I}}(Y)-Y p_{\mathrm{I}}(Y)+t y+t^{*} y^{*} \equiv C S_{\mathrm{I}}+t y+t^{*} y^{*}, \\
(11.3) & S W_{\mathrm{F}}\left(t, t_{\mathrm{F}}, t^{*}, t_{\mathrm{H}}\right) \equiv u_{\mathrm{F}}(Z)-Z p_{\mathrm{F}}(Z)+\pi^{*}+t_{\mathrm{F} Z} \equiv C S_{\mathrm{F}}+\pi^{*}+t_{\mathrm{F} Z},
\end{array}
$$

where $C S_{i}(i=\mathrm{H}, \mathrm{I}, \mathrm{F})$ represents the consumers' surplus of country $i$. Then the optimal tariff rate(s) of each country, which are defined as $t_{\mathrm{H}}^{o p} \equiv \arg \max S W_{\mathrm{H}}\left(t, t_{\mathrm{F}}, t^{*}, t_{\mathrm{H}}\right),\left(t^{o p}, t^{* o p}\right) \equiv \arg \max S W_{\mathrm{I}}\left(t, t_{\mathrm{F}}, t^{*}, t_{\mathrm{H}}\right)$, and $t_{\mathrm{F}}^{o p} \equiv \arg \max S W_{\mathrm{F}}\left(t, t_{\mathrm{F}}, t^{*}, t_{\mathrm{H}}\right)$, can be expressed as follows by using equations (6.1)-(6.6):

$$
\begin{aligned}
& \text { (12.1) } t_{\mathrm{H}}^{o p}=\left(1 / x_{4}^{*}\right)\left[X p_{\mathrm{H}}{ }^{\prime} X_{4}-\left(x p_{\mathrm{H}}{ }^{\prime} x_{4}^{*}+y p_{\mathrm{I}}^{\prime} y^{*}+z p_{\mathrm{F}}{ }^{\prime} z_{4}^{*}\right)-x^{*}\right], \\
& (12.2) \quad t_{\mathrm{F}}^{o p}=\left(1 / z_{2}\right)\left[Z p_{\mathrm{F}}^{\prime} Z_{2}-\left(z^{*} p_{\mathrm{F}}^{\prime} z_{2}+y^{*} p_{\mathrm{I}}^{\prime} y_{2}+x^{*} p_{\mathrm{H}}{ }^{\prime} x_{2}\right)-z\right], \\
& \text { (12.3) }\left[\begin{array}{c}
t^{o p} \\
t^{* o p}
\end{array}\right]=\Lambda^{-1}\left[\begin{array}{c}
y\left(p_{\mathrm{I}}^{\prime} \Lambda-y^{*} *_{3}\right)+y^{*}\left(p_{\mathrm{I}}^{\prime} \Lambda+y^{*} *_{1}\right) \\
y\left(p_{\mathrm{I}}^{\prime} \Lambda+y_{3}\right)+y^{*}\left(p_{\mathrm{I}}^{\prime} \Lambda-y_{1}\right)
\end{array}\right],
\end{aligned}
$$

where $\Lambda \equiv y_{1} y^{*_{3}}-y_{3} y^{*_{1}}=\left(A_{22} A_{55}-A_{25} A_{52}\right) / \operatorname{det}(A)^{2}>0^{(8)}, y_{1} \equiv \partial y / \partial t, z_{2} \equiv \partial z / \partial t_{\mathrm{F}}, y_{3} \equiv \partial y / \partial t^{*}$, and $x_{4} \equiv \partial x / \partial t_{\mathrm{H}}$.

\subsection{The welfare effects of a reduction in tariff rate of country I}

Now in this sub-section, we shall analyze the welfare effects of a discriminatory tariff change and those of a uniform tariff change. First let us investigate the effects of a change in $t$ on the welfare of the exporting countries. These effects are measured by the following expressions:

$$
\partial S W_{\mathrm{H}} / \partial t=-X p_{\mathrm{H}}^{\prime} X_{1}+\left[x p_{\mathrm{H}}^{\prime} x *_{1}+y p_{\mathrm{I}}^{\prime} y^{*_{1}}-y+z p_{\mathrm{F}} z^{*_{1}}\right]+t_{\mathrm{H}} x_{1}^{*_{1}},
$$


Hisayuki Okamoto : Pareto Improving Tariff Reduction Scheme in an Imperfectly Competitive Model of Trade: A Three-Country Case

(13.2) $\partial S W_{\mathrm{F}} / \partial t=-Z p_{\mathrm{F}}^{\prime} Z_{1}+\left[z^{*} p_{\mathrm{F}}^{\prime} z_{1}+y^{*} p_{\mathrm{I}}^{\prime} y_{1}+x^{*} p_{\mathrm{H}}{ }^{\prime} x_{1}\right]+t_{\mathrm{F}} z_{1}$.

In the RHS of the above formulas, the first term of the each expression represents the consumers' surplus change, the second term denotes the profit change, and the last term expresses the tariff revenue change. From (9), we see the first terms of both (13.1) and (13.2) are negative if and only if $\varepsilon_{\mathrm{I}}>0$. This means that a reduction in $t$ increases the consumers' surplus of the both exporting countries $\left(=\partial C S_{i} / \partial t\right)$ if and only if $\varepsilon_{\mathrm{I}}>0$. On the other hand, the second term of $(13.1)(=\partial \pi / \partial t)$ is negative while that of $(13.2)(=\partial \pi * / \partial t)$ positive. This reflects a change in relative position of international competition of the two duopolists. The last terms of (13.1) and (13.2) are negative or positive depending on what kind of import "tariffs" are imposed. Thus, the social welfare of country $\mathrm{H}$ is increased by a reduction in $t$ if $\varepsilon_{\mathrm{I}}>0$ and the effect of positive tariff revenue change does not dominate. The latter condition is assured if the marginal costs of the two firms are not so different: $C^{\text {' }}$ $-C^{*} \leqq x^{*} p_{\mathrm{H}}{ }^{\prime}$. Because the second and the last terms of (13.1) can be rewritten as

$$
\begin{aligned}
{[\partial \pi / \partial t]+t_{\mathrm{H}} x^{*}{ }_{1} } & =x *_{1}\left(x p_{\mathrm{H}}{ }^{\prime}+t_{\mathrm{H}}\right)+\left[y p_{\mathrm{I}} y^{*_{1}}-y+z p_{\mathrm{F}} z^{*_{1}}\right], \\
& =x^{*_{1}}\left(x^{*} p_{\mathrm{H}}{ }^{\prime}+C^{\prime}-C^{*}\right)+\left[y p_{\mathrm{I}}^{\prime} y^{*_{1}}-y+z p_{\mathrm{F}} z^{*_{1}}\right] .
\end{aligned}
$$

On the other hand, the social welfare of country F may increase or decrease depending on whether the effect of producer's surplus change dominate or not. In this context, non-constancy of marginal cost plays an important role. In order to see this, let us consider the special case of $C^{\prime \prime}=C^{* \prime \prime}=0$. In this case, from Appendix A.3, (13) becomes as follows:

$$
\begin{aligned}
& \text { (13.3) } \partial S W_{\mathrm{H}} / \partial t=-y\left(h_{\mathrm{I}}+2 h_{\mathrm{I}}^{*}+p_{\mathrm{I}}{ }^{\prime}\right) /\left(h_{\mathrm{I}}+h_{\mathrm{I}}^{*}+p_{\mathrm{I}}{ }^{\prime}\right)<0, \\
& \text { (13.4) } \partial S W_{\mathrm{F}} / \partial t=y^{*}\left(h_{\mathrm{I}}^{*}+p_{\mathrm{I}}{ }^{\prime}\right) /\left(h_{\mathrm{I}}+h_{\mathrm{I}}{ }^{*}+p_{\mathrm{I}}{ }^{\prime}\right)>0 .
\end{aligned}
$$

This reflects that each producer's supply of the good $\mathrm{M}$ to each market does not change except to the market of country $\mathrm{I}$ in this special case. That is, when the marginal costs of both duopolists are constant, $x, x^{*}, z$, and $z^{*}$ do not alter, despite a shift in the net marginal revenue curve caused by a change in $t$. Hence, there are no other ways to change the social welfare of both exporting countries except the producer's surplus changes and so the interests of the two countries conflict with each other.

By the way, the effects of a change in $t$ on the welfare of the importing country is measured by

$$
\text { (13.5) } \partial S W_{\mathrm{I}} / \partial t=y_{1}\left(-Y p_{\mathrm{I}}{ }^{\prime}+t\right)+y^{*}\left(-Y p_{\mathrm{I}}{ }^{\prime}+t^{*}\right)+y .
$$

From (12.3), the following inequality can be proved very easily.

$$
\text { (13.6) } \partial S W_{\mathrm{I}} / \partial t<0 \text { if } t>t^{o p}, t^{*}=t^{* o p} \text {. }
$$

Thus, when the discriminatory tariff for country $\mathrm{H}$ is overtaxed, while the discriminatory tariff for country $\mathrm{F}$ is optimally levied, a reduction of discriminatory tariff for country $\mathrm{H}$ necessarily raises the welfare of country I.

The above observation leads the following proposition.

Theorem 4: The effects of a change in ton the social welfare of each country can be represented, in general, as (13.1), (13.2), and (13.5). A reduction in $t$ can increase the world welfare if $t>t^{o p}$ and $t^{*}=t^{* o p}$, when the effect of tariff revenue change is small enough in each country's welfare change, the effect of producer's surplus change does not dominate in country $F$ 's welfare change, and $\varepsilon_{I}>0$ is satisfied.

As the effects of change in $t^{*}$ is symmetric to $t$, we can readily derive the following corollary. 
Corollary 4. 1: A reduction in $t^{*}$ can increase the world welfare if $t^{*}>t^{*}(0)$ and $t=t^{\prime \prime p}$, when the effect of tariff revenue change is small enough in each country's welfare change, the effect of producer's surplus change does not dominate in country $H^{\prime}$ 's welfare change, and $\varepsilon_{I}^{*}>0$ is satisfied.

Next, let us consider the welfare effects of the uniform tariff change. The effects of a change in the uniform tariff rate $t_{1}$ on the welfare of the exporting countries are measured by the following expressions:

$$
\text { (14.1) } \begin{aligned}
\partial S W_{\mathrm{H}} / \partial t_{\mathrm{I}}= & -X p_{\mathrm{H}}{ }^{\prime}\left(X_{1}+X_{3}\right)+\left[x p_{\mathrm{H}}{ }^{\prime}\left(x^{*}{ }_{1}+x_{3}\right)+y p_{\mathrm{I}}{ }^{\prime}\left(y_{1}+y_{3} *_{3}\right)-y\right. \\
& \left.+z p_{\mathrm{F}}{ }^{\prime}\left(z^{*}{ }_{1}+z^{*}\right)\right]+t_{\mathrm{H}}\left(x^{*}{ }_{1}+x^{*}\right), \\
\text { (14.2) } \partial S W_{\mathrm{H}} / \partial t_{\mathrm{I}}= & -Z_{\mathrm{F}_{\mathrm{F}}}{ }^{\prime}\left(Z_{1}+Z_{3}\right)+\left[z^{*} p_{\mathrm{F}}{ }^{\prime}\left(z_{1}+z_{3}\right)+y^{*} p_{\mathrm{I}}{ }^{\prime}\left(y_{1}+y_{3}\right)-y^{*}\right. \\
& \left.+x^{*} p_{\mathrm{H}}{ }^{\prime}\left(x_{1}+x_{3}\right)\right]+t_{\mathrm{F}}\left(z_{1}+z_{3}\right) .
\end{aligned}
$$

In the above formulas, the first term of the each expression represents the consumers' surplus change, the second term denotes the profit change, and the last term expresses the tariff revenue change. We see the signs of the above expressions can be either negative or positive.

To simplify the analysis, let us consider the special example of $C^{\prime \prime}=C^{* \prime \prime}=0$. In this special case, (14.1)(14.2) becomes as follows :

$$
\begin{aligned}
& \text { (14.3) } \partial S W_{\mathrm{H}} / \partial t_{\mathrm{I}}=-y p_{\mathrm{I}}{ }^{\prime} \phi_{\mathrm{I}}\left(2 h_{\mathrm{I}}^{*}\right) / \operatorname{det}(A) \leqq 0, \\
& \text { (14.4) } \partial S W_{\mathrm{F}} / \partial t_{\mathrm{I}}=-y^{*} p_{\mathrm{I}}{ }^{\prime} \phi_{\mathrm{I}}\left(2 h_{\mathrm{I}}\right) / \operatorname{det}(A) \leqq 0 .
\end{aligned}
$$

It should be emphasized that these equations hold at any $\left(t_{\mathrm{F}}, t_{\mathrm{I}}, t_{\mathrm{H}}\right)$, including $\left(t_{\mathrm{F}}, t_{\mathrm{I}}, t_{\mathrm{H}}\right) \neq 0$. From equations (14.3)-(14.4) it is observed that a reduction in $t_{\mathrm{I}}$ causes to increase the welfare of every exporting country when $h_{\mathrm{I}}$ and $h_{\mathrm{I}}^{*}$ are negative. Thus, both exporting countries benefit from a reduction in the uniform tariff rate of the importing country I. Furthermore, in this special case, we have

$$
\text { (14.5) } \partial S W_{\mathrm{I}} / \partial t_{\mathrm{I}}=\phi_{\mathrm{I}}\left[Y p_{\mathrm{I}}{ }^{2}+t_{\mathrm{I}}\left(h_{\mathrm{I}}+h_{\mathrm{I}}^{*}\right)\right] / \operatorname{det}(A)<0 \quad \text { iff } t_{I} \neq t_{I}^{o p} \text { and } h_{\mathrm{I}} \cdot h_{\mathrm{I}}^{*} \neq 0 .
$$

Thus, when the actual value of $t_{\mathrm{I}}$ is higher than the optimal value, a reduction in $t_{\mathrm{I}}$ increases the welfare of every country. This leads to the following proposition.

Theorem 5: If $C^{\prime \prime}=C^{* \prime}=0$, the effects of the uniform tariff change on the welfare of each country can be represented as (14.3)-(14.5). Thus, a reduction of the uniform tariff $t_{I}$ increases the welfare of every country if $t_{I}>$ $t_{I}^{o p}$.

Note that, as we have already seen in Remark 1 of section $4.1, h_{\mathrm{I}}$ and $h_{\mathrm{I}}^{*}$ can be positive. That is the case where the demand function of country I is convex to the origin. In that case, the welfare effect of countries $\mathrm{H}$ and $\mathrm{F}$ can be reversed. Thus, Theorem 9 yields the following corollary.

Corollary 5. 1: When $C^{\prime \prime}=C^{* \prime \prime}=0$, an increase in $t_{1}$, which is less than the optimal level $t_{l}^{\text {op }}$, increases the welfare of every country if $h_{I}$ and $h_{I}{ }^{*}$ are positive and satisfy the conditions $h_{I}+p_{I}{ }^{\prime}<0$ and $h_{I}{ }^{*}+p_{I}{ }^{\prime}<0$.

\subsection{The welfare effects of a reduction in $t_{\mathrm{H}}$ and $t_{\mathrm{F}}$}

In this sub-section the effects of a change in $t_{\mathrm{H}}$ and $t_{\mathrm{F}}$ on the welfare of each country will be examined. First, let us investigate the effects of a change in $t_{\mathrm{H}}$ on the world welfare. From equations (11) we have the following expressions:

(15.1) $\partial S W_{\mathrm{F}} / \partial t_{\mathrm{H}}=-Z p_{\mathrm{F}}{ }^{\prime} Z_{4}+\left[z^{*} p_{\mathrm{F}}{ }^{\prime} z_{4}+y^{*} p_{\mathrm{I}}{ }^{\prime} y_{4}+x^{*} p_{\mathrm{H}}{ }^{\prime}\left(x_{4}-1\right)\right]+t_{\mathrm{F}} z_{4}$, 
Hisayuki Okamoto : Pareto Improving Tariff Reduction Scheme in an Imperfectly Competitive Model of Trade: A Three-Country Case

(15.2) $\partial S W_{\mathrm{I}} / \partial t_{\mathrm{H}}=-Y p_{\mathrm{I}}^{\prime} Y_{4}+t_{\mathrm{I}} Y_{4}$.

From (12) the first and the second terms of the RHS of (15.1) are negative if and only if $\varepsilon_{\mathrm{H}}>0$, while the third term of the RHS of (15.1) is positive if $t_{\mathrm{F}}$ is positive and at least one of $C^{\prime \prime}$ and $C^{* \prime \prime}$ is negative. Thus, there exists a positive value of $t_{\mathrm{F}}$ which makes $\partial S W_{\mathrm{F}} / \partial t_{\mathrm{H}}=0$, if $\varepsilon_{\mathrm{H}}>0$ and at least one of $C^{\prime \prime}$ and $C^{* \prime}$ is negative. Let us define the value of this $t_{\mathrm{F}}$ as $t_{\mathrm{FH}}$. Then, assuming $\varepsilon_{\mathrm{H}}>0$ and at least one of $C^{\prime \prime}$ and $C^{* \prime \prime}$ is negative, $\partial S W_{\mathrm{F}}$ $\partial t_{\mathrm{H}}$ becomes negative if $t_{\mathrm{F}}$ is smaller than $t_{\mathrm{FH}}>0$. On the other hand, the first term of the RHS of (15.2) is negative if and only if $\varepsilon_{\mathrm{H}}>0$, whereas the second term of the RHS of (15.2) becomes positive, if $t_{\mathrm{I}}$ is negative and $\varepsilon_{\mathrm{H}}>0$ as well as at least one of $C^{\prime \prime}$ and $C^{* \prime}$ is negative. Thus, there exists some negative value of $t_{\mathrm{I}}$ which brings $\partial S W_{\mathrm{I}} / \partial t_{\mathrm{H}}=0$, if $\varepsilon_{\mathrm{H}}>0$ and at least one of $C^{\prime \prime}$ and $C^{* \prime \prime}$ is negative. Let us define the value of this $t_{\mathrm{I}}$ as $t_{\mathrm{IH}}$. Then, assuming $\varepsilon_{\mathrm{H}}>0$ and at least one of $C^{\prime \prime}$ and $C^{* \prime \prime}$ is negative, $\partial S W_{\mathrm{I}} / \partial t_{\mathrm{H}}$ becomes negative if $t_{\mathrm{I}}$ is greater than $t_{\mathrm{IH}}<0$. Under these assumptions, a reduction in $t_{\mathrm{H}}$ causes a rise in welfare of countries $\mathrm{F}$ and $\mathrm{I}$. Furthermore we have

(15.3) $\partial S W_{\mathrm{H}} / \partial t_{\mathrm{H}}=-X p_{\mathrm{H}} X_{4}+\left[x p_{\mathrm{H}}^{\prime} x^{*}{ }_{4}+y p_{1}^{\prime} y^{*}{ }_{4}+z p_{\mathrm{F}}{ }^{*} z_{4}\right]+x^{*}+t_{\mathrm{F}} x_{4}$

$$
\leqq 0 \quad \text { iff } \quad t_{\mathrm{H}} \geqq t_{\mathrm{H}}^{o p},
$$

where $t_{\mathrm{H}}^{o p}$ is defined in (12.1). Thus if $t_{\mathrm{H}}$ is greater than its optimal value, a reduction in $t_{\mathrm{H}}$ benefits country $\mathrm{H}$ as well and so we have the following theorem.

Theorem 6: The effects of country H's tariff change on the welfare of each country can be represented as equations (15.1)-(15.3). Therefore, if $\varepsilon_{H}>0$, at least one of $C^{\prime \prime}$ and $C^{* \prime \prime}$ is negative, $t_{F}<t_{F H}, t_{l}>t_{I H}$, and $t_{H}>t_{H}^{o p}$, a reduction in the tariff rate $t_{H}$ increases the world welfare. Moreover, even if $t_{H}=t_{H}{ }^{o p}$, an infinitesimal reduction of $t_{H}$ can be a Pareto superior policy for the world as a whole.

Remark: In Theorem 10, when $C^{\prime \prime}=C^{* \prime}=0$, we can obtain the same sort of result without $t_{\mathrm{F}}<t_{\mathrm{FH}}$ and $t_{\mathrm{l}}>$ $t_{\mathrm{IH}}$. Because, by substituting the relevant values of $A_{i j}$ 's in Appendix A.3 into (15.1)-(15.3) in this case, we have the following:

$$
\begin{aligned}
\partial S W_{\mathrm{F}} / \partial t_{\mathrm{H}} & =-x^{*}\left(2 h_{\mathrm{H}}+h_{\mathrm{H}}{ }^{*}+p_{\mathrm{H}}{ }^{\prime}\right) /\left(h_{\mathrm{H}}+h_{\mathrm{H}}{ }^{*}+p_{\mathrm{H}}{ }^{\prime}\right)<0 \\
\partial S W_{\mathrm{I}} / \partial t_{\mathrm{H}} & =0 \\
\partial S W_{\mathrm{H}} / \partial t_{\mathrm{H}} & =\left[x h_{\mathrm{H}}+x^{*}\left(h_{\mathrm{H}}+h_{\mathrm{H}}{ }^{*}\right)+t_{\mathrm{H}}\left(1 / p_{\mathrm{H}}{ }^{\prime}\right)\left(h_{\mathrm{H}}+p_{\mathrm{H}}{ }^{\prime}\right)\right] /\left(h_{\mathrm{H}}+h_{\mathrm{H}}^{*}+p_{\mathrm{H}}{ }^{\prime}\right) \\
& \leqq 0 \quad \text { iff } \quad t_{\mathrm{H}} \geqq t_{\mathrm{H}}{ }^{o p} .
\end{aligned}
$$

Thus, we have the following corollary:

Corollary 6.1: The effects of country H's tariff change on the welfare of each country can be represented as equations (15.4)-(15.6) when $C^{\prime \prime}=C^{* \prime}=0$. Thus, if $t_{H} \geqq t_{H}{ }^{o p}$, a reduction in the tariff rate $t_{H}$ is a Pareto superior policy for the world as a whole.

By making the same sort of analysis of the change in $t_{\mathrm{F}}$, we have the following equations:

$$
\begin{aligned}
& \partial S W_{\mathrm{H}} / \partial t_{\mathrm{F}}=-X p_{\mathrm{F}}^{\prime} X_{2}+\left[x p_{\mathrm{H}}^{\prime} x *_{2}+y p_{\mathrm{I}}^{\prime} y_{2}^{*_{2}}+z p_{\mathrm{F}}^{\prime}\left(z *_{2}-1\right)\right]+t_{\mathrm{H}} x_{2} \\
& \leqq 0 \quad \text { if } \quad \varepsilon_{\mathrm{F}}>0 \quad \text { and } \quad t_{\mathrm{H}} \leqq t_{\mathrm{HF}}, \\
& \text { (16.2) } \partial S W_{\mathrm{I}} / \partial t_{\mathrm{F}}=-Y p_{\mathrm{I}}{ }^{\prime} Y_{2}+t_{\mathrm{I}} Y_{2} \leqq 0 \quad \text { if } \quad \varepsilon_{\mathrm{F}}>0 \quad \text { and } t_{\mathrm{I}} \geqq t_{\mathrm{IF}} \text {, } \\
& \text { (16.3) } \partial S W_{\mathrm{F}} / \partial t_{\mathrm{F}}=-Z p_{\mathrm{F}}{ }^{\prime} Z_{2}+\left[z^{*} p_{\mathrm{F}}{ }^{\prime} z_{2}+y^{*} p_{\mathrm{I}}{ }^{\prime} y_{2}+x^{*} p_{\mathrm{H}}{ }^{\prime} x_{2}\right]+z+t_{\mathrm{F}} z_{2} \leqq 0 \text { iff } t_{\mathrm{F}} \geqq t_{\mathrm{F}}^{o p} \text {, }
\end{aligned}
$$


where $t_{\mathrm{HF}}$ is some positive value of $t_{\mathrm{H}}$ which brings $\partial S W_{\mathrm{H}} / \partial t_{\mathrm{F}}=0$ and $t_{\mathrm{IF}}$ is some negative value of $t_{\mathrm{I}}$ which brings $\partial S W_{\mathrm{I}} / \partial t_{\mathrm{F}}=0$, if $\varepsilon_{\mathrm{F}}>0$ and at least one of $C^{\prime \prime}$ and $C^{* \prime \prime}$ is negative. Thus we obtain the following proposition:

Theorem 7: The effects of country F's tariff change on the welfare of each country can be represented as equations (16.l)-(16.3). Therefore, if $\varepsilon_{F}>0$, at least one of $C^{\prime \prime}$ and $C^{* \prime \prime}$ is negative, $t_{H}\left\langle t_{H F}, t_{l}>t_{I F}\right.$, and $t_{F}>t_{F}(p)$, a reduction in the tariff rate $t_{F}$ increases the welfare of each country. Moreover, even if $t_{F}=t_{F}{ }^{o p}$, an infinitesimal reduction of $t_{F}$ can be a Pareto superior policy for the world as a whole.

Remark: In Theorem 11, if $C^{\prime \prime}=C^{* \prime \prime}=0$, we can get the same sort of result without $t_{\mathrm{H}}<t_{\mathrm{HF}}$ and $t_{\mathrm{l}}>t_{\mathrm{IF}}$. Because, in this case, substituting the relevant values of $A i_{j}$ 's in Appendix A.3 into expressions (16.1)-(16.3) yields

(16.4) $\partial S W_{\mathrm{H}} / \partial t_{\mathrm{F}}=-z\left(h_{\mathrm{F}}+2 h_{\mathrm{F}}{ }^{*}+p_{\mathrm{F}}{ }^{\prime}\right) /\left(h_{\mathrm{F}}+h_{\mathrm{F}}^{*}+p_{\mathrm{F}}{ }^{\prime}\right)<0$,

(16.5) $\partial S W_{\mathrm{I}} / \partial t_{\mathrm{F}}=0$,

(16.6) $\partial S W_{\mathrm{F}} / \partial t_{\mathrm{F}}=\left[z^{*} h_{\mathrm{H}}^{*}+z\left(h_{\mathrm{F}}+h_{\mathrm{F}}^{*}\right)+t_{\mathrm{F}}\left(1 / p_{\mathrm{F}}{ }^{\prime}\right)\left(h_{\mathrm{F}}^{*}+p_{\mathrm{F}}{ }^{\prime}\right)\right] /\left(h_{\mathrm{F}}+h_{\mathrm{F}}{ }^{*}+p_{\mathrm{F}}{ }^{\prime}\right)$

$\leqq 0 \quad$ iff $\quad t_{\mathrm{F}} \geqq t_{\mathrm{F}}^{o p}$.

Thus, we have the following corollary:

Corollary 7.1: The effects of country F's tariff change on the welfare of each country can be represented as equations (16.4)-(16.6) when $C^{\prime \prime}=C^{* \prime \prime}=0$. Thus, if $t_{F} \geqq t_{F}^{o p}$, a reduction in the tariff rate $t_{H}$ is a Pareto superior policy for the world as a whole.

\section{Concluding Remarks}

In this paper we have constructed and analyzed the nature of the two-good and three-country trade model that seems to be very suitable to analyze the present world trade. First, we have shown that under a set of conditions on the non-linear cost functions and the non-linear demand functions, the uniqueness of the Cournot equilibrium is assured. (Theorem 1) Then we proceed to the comparative static analysis of tariff changes and determine the signs of the effects of tariff changes on consumption in each country, production of every firm, and the intraindustry trade between developed countries can be specified. (Theorems 2 and 3 and Corollaries 2.1 and 3.1) The results are quite different from Okamoto and Yoshida (1994) who assume increasing marginal cost of each duopolist. Most remarkable difference is that a rise in one of the tariffs in the importing country I substantially reduces the target duopolist's production and raises the other duopolist's production in the model, while in the Okamoto-Yoshida model the effects of changes in both duopolists' outputs are in the same direction as in the present model but the degree of them are rather moderate. This difference creates the big difference in the propositions concerning the effects of tariff.

Second, we have considered the implications of a tariff change on the world welfare and shown that a reduction in one the tariffs of exporting countries can increase the welfare of the rest of the world. Furthermore if the reduced rate of tariff is greater than the optimal level, this also increases the welfare of the country itself. (Theorems 4 and 5 and Corollaries 4.1 and 5.1) On the other hand, a reduction in the importing country's tariff rate 
Hisayuki Okamoto : Pareto Improving Tariff Reduction Scheme in an Imperfectly Competitive Model of Trade: A Three-Country Case

may increase the welfare of the rest of the world. (Theorem 6 and Corollary 6.1) In a special case of $C^{\prime \prime}=C^{* \prime \prime}=$ 0 , we have shown that this is the case. (Theorem 7) These result are also quite different from what Okamoto and Yoshida (1994) have obtained. They have pointed out that a rise in the tariff rate of importing country can raise the world welfare when the marginal cost of imperfectly competitive good exhibits increasing in both duopolists. Thus the obtained results are very sensitive to the marginal cost conditions.

* The author is grateful to Professor Alan Woodland of the University of Sydney for his comments on earlier version of this paper, Okamoto (1994).

\section{Notes}

(1) We assume that the international payments are settled by numeraire good. So that the numeraire good can be regarded as 'money'.

(2) An $n \times n$ matrix $A=\left(a_{i j}\right)$ is said to have dominant diagonals if there exist $d_{j}>0(j=1, \ldots, n)$ such that $d_{j}\left|a_{j j}\right|$ $>\sum_{i \neq j} d_{i}\left|a_{j i}\right|$ for any $j$. A matrix with dominant diagonals is non-singular. (See McKenzie (1960, p.49) for the proof.)

(3) An $n \times n$ matrix is said to be an N-P matrix if its principal minors of order $\mathrm{r}$ have the sign of $(-1)^{r}(r=1, \ldots, n)$. (For the definition of N-P matrix see for example Kemp and Kimura (1978).)

(4) If the Jacobian matrix of an equation system is an N-P matrix, then the solution of the system is unique. (See Nikaido (1968, p.371) and Kemp and Kimura (1978, p.88).)

( 5 ) Uekawa and Ohta (1993) has also solved the problem of the Cournot equilibrium of the international trade with intra-industry trade in the case of increasing marginal cost.

(6) Appendix of this paper is available upon request. Please contact the author.

(7) Assumption A.4 determines the asymptotic lines of $\varepsilon_{\mathrm{I}}$ and the general shape of $\varepsilon_{\mathrm{I}}$.

(8) Because $\left|A_{22}\right|-\left|A_{25}\right|=-\left(A_{22}+A_{25}\right)>0$ and $\left|A_{55}\right|-\left|A_{52}\right|=-\left(A_{55}+A_{52}\right)>0$ due to equations in (9) and (10), we obtain $A_{22} A_{55}=\left|A_{22}\right|\left|A_{55}\right|>\left|A_{25}\right|\left|A_{52}\right|=A_{25} A_{52}$, i.e., $\Lambda>0$.

\section{References}

Brander, J. A. and P. Krugman, 1983, “A 'Reciprocal-Dumping' Model of International Trade,' Journal of International Economics 15, 313-321.

Brander, J.A. and B.J. Spencer, 1984a, "Tariff Protection and Imperfect Competition," in: Henry Kierzkowski, ed., Monopolistic Competition and International Trade (Oxford University Press, Oxford), 194-206.

Brander, J.A. and B.J. Spencer, 1984b, "Exporting Subsidies and International Market Share Rivalry," Journal of International Economics 18, 83-100.

Cheng, L. K., 1988, “Assisting Domestic Industries under International Oligopoly : The Relevance of the Nature of Competition to Optimal Policies," American Economic Review 78, 746-758.

Diewert, W.E., A.H. Turunen-Red, and A.D. Woodland, 1991, "Tariff Reform in a Small Open Multi-Household Economy with Domestic Distortions and Nontraded Goods," International Economic Review 32, 937-957.

Dixit, A., 1984, "International Trade Policies for Oligopolistic Industries," Economic Journal 94, 1-18.

Dixit, A., 1988, “Anti-Dumping and Countervailing Duties under Oligopoly,” European Economic Review 34, 55-68.

Eaton, J. and G.M.Grossman, 1986, "Optimal Trade and Industrial Policy under Oligopoly, Quarterly Journal of Econom- 
ics $101,383-406$.

Gatsios, K., 1990, "Preferential Tariffs and the 'Most Favoured Nation' Principle: A Note," Journal of International Economics $28,365-373$.

Hahn, F.H., 1962, “The Stability of the Cournot Oligopoly Solution,” Review of Economic Studies 32, 329-331.

Krugman, P., 1984, "Import Protection as Export Promotion: International Competition in the Presence of Oligopolies and Economies of Scale," in H. Kierzkowski, ed., Monomplistic Competition and International Trade (Oxford University Press, Oxford), 180-193.

Kemp, M.C, and Y. Kimura, 1978, Introduction to Mathematical Economics (Springer-Verlag, Berlin et al.).

McKenzie, L. W., 1960, "Matrix with Dominant Diagonals and Economic Theory, in : K.J. Arrow, S. Karlin and P. Suppes, eds., Mathematical Methods in the Social Science (Stanford University Press, Stanford), 47-62.

Nikaido, H., 1968, Convex Structures and Economic Theory (Academic Press, New York).

Okamoto, H., 1994, “Imperfect Competition, Intra-Industry Trade, and Non-Linear Demand and Cost Functions: A Comprehensive Analysis of Three-Country Model of Trade," Econometrics Discussion Papers \#94-08, University of Sydney.

Okamoto, H., 1998, "International Duopoly and Trade Policies under Budget Constraint: Non-Linear Cost and Demand Function, Journal of International Cooperation Studies 6, 115-136.

Okamoto, H. and C. Yoshida, 1994, “A Three-Country Trade Model under Imperfect Competition: Non-Linear Cost Function Case," Journal of Economics 60, 155-176.

Okuguchi, K., 1990a, “Transport Cost in Cournot Duopoly with Several Markets,” Studies in Regional Science 20, 95105.

Okuguchi, K., 1990b, “Cournot Duopoly with Several Markets," Regional Science and Urban Economics 20, 305-311.

Uekawa, Y., 1990, "The Relevance of the Nature of Competition to Optimal Policies under International Oligopoly and Nonlinear Cost Functions - A General Equilibrium Analysis: Bertrand vs. Cournot--, Discussion Paper \#5, Chukyo University.

Uekawa, Y. and H. Ohta, 1993, "Imperfect Competition and Existence of the General Equilibrium Solution under IntraIndustry Trade," in Herberg, H. and N.Van Long, eds., Trade Welfare, and Economic Policies, (University of Michigan Press, Michigan), 255-266. 